\title{
Preparation and modification of hydrous thick cobalt oxide layers: voltammetric characteristics of rough $\mathrm{Co}_{3} \mathrm{O}_{4}$-spinel-type electrodes
}

\author{
T. KESSLER, A. VISINTÍN, W. E. TRIACA, A. J. ARVIA* \\ Instituto de Investigaciones Fisicoquimicas Teóricas y Aplicadas (INIFTA), Facultad de Ciencias Exactas, \\ Universidad Nacional de La Plata, Casilla de Correo 16, Sucursal 4, (1900) La Plata, Argentina
}

\author{
M. R. GENNERO DE CHIALVO \\ Programa de Electroquimica Aplicada e Ingeniería Electroquimica (PRELINE), Facultad de Ingenieria \\ Química, Universidad Nacional del Litoral, Santiago del Estero 2829, (3000) Santa Fe, Argentina
}

Received 17 September 1990; revised 10 December 1990

\begin{abstract}
The application of a periodic perturbing potential to a cobalt electrode immersed in alkaline solutions at room temperature allows accumulation of a hydrous cobalt hydroxide overlayer which becomes a precursor to the production of a rough $\mathrm{Co}_{3} \mathrm{O}_{4}$ spinel film through subsequent thermal treatment at $480^{\circ} \mathrm{C}$. The optimal working conditions for the application of this procedure are discussed. The properties of the resulting overlayers were determined through voltammetry, X-ray analysis, infrared spectroscopy, thermal gravimetric and differential thermal analysis, and SEM micrography. The explanation of the entire process is given in terms of sequential electrochemical oxidation and reduction reactions involving different $\mathrm{Co}$-containing species. The electroreduction reactions including the HER, play an important role in determining the characteristics of the resulting $\mathrm{Co}_{3} \mathrm{O}_{4}$ overlayer.
\end{abstract}

\section{Introduction}

Hydrous metal oxide layers can be easily produced on several metals by applying periodic potential treatments within certain potential and frequency ranges [1-6]. These layers are electrochemically active under potentiodynamic conditions and exhibit drastic voltammetric changes due to modifications of the layer structure.

It was recently reported that an incipient cobalt oxide spinel-structure overlayer with a relatively large electrocatalytic active surface area can be produced by applying a periodic potential treatment to cobalt electrodes immersed in alkaline solution [5]. The characteristics of the potential routine used in the preparation of the electrode and the composition of the solution determine the electrochemical behaviour of the resulting cobalt oxide layer. These types of cobalt oxide electrodes exhibit a clear electrocatalytic activity for the oxygen evolution reaction [6].

The present work describes the preparation procedure of rough $\mathrm{Co}_{3} \mathrm{O}_{4}$-spinel-type electrodes from thick hydrous cobalt oxide layers, the composition of the different cobalt oxide layers resulting either electrochemically or from a thermal treatment, and the probable electrochemical reactions related to these processes.

\section{Experimental details}

Runs were made in a conventional two compartment/ three electrode Pyrex glass electrochemical cell of about $0.1 \mathrm{dm}^{3}$ capacity. The working electrodes $(0.3$ to $0.5 \mathrm{~cm}^{2}$ apparent area) were made from cobalt wires (Johnson Matthey, specpure quality). The potential of the working electrode was measured against a $\mathrm{Hg}$ / $\mathrm{HgO} / 1 \mathrm{M} \mathrm{NaOH}$ reference electrode $\left(E^{0}=0.925 \mathrm{~V}\right.$ (against $\mathrm{RHE}$ ), at $25^{\circ} \mathrm{C}, \mathrm{d} E / \mathrm{d} T=0.00056 \mathrm{~V} \mathrm{~K}^{-1}$ ) connected to the rest of the cell through a LugginHaber capillary tip $0.2 \mathrm{~mm}$ dia. located at about $0.1 \mathrm{~mm}$ from the working electrode surface. The counterelectrode consisted of a $\mathrm{Pt}$ spiral of $\sim 10 \mathrm{~cm}^{2}$ geometric area surrounding the working electrode concentrically. The $1 \mathrm{M} \mathrm{NaOH}$ solution was prepared from $\mathrm{NaOH}$ (Merck p.a.) and triply distilled $\mathrm{CO}_{2}$-free water. The electrolyte solution was kept continuously under nitrogen. The runs were made at $30^{\circ} \mathrm{C}$.

Each run comprised the working electrode pretreatment, the hydrous cobalt hydroxide layer preparation through the application of a repetitive square wave potential routine (RSWPR), and the determination of the voltammetric characteristics of the new electrode surface.

The working electrode pretreatment comprised 5 min etching in $50 \% \mathrm{H}_{2} \mathrm{SO}_{4}$, washing and rinsing 
in triply distilled water, and finally $5 \mathrm{~min}$ potential cycling at $0.1 \mathrm{~V} \mathrm{~s}^{-1}$ between $-0.32 \mathrm{~V}$ and $0.64 \mathrm{~V}$, in $1 \mathrm{M} \mathrm{NaOH}$ to attain a stabilized voltammetric profile similar to that reported in the literature $[7,10]$.

The RSWPR treatment involved the application of either a time-symmetric or time-asymmetric signal between an upper, $E_{\mathrm{u}}$, and a lower potential, $E_{1}$, at the frequency, $f$, for the time $t$. For the symmetric signal, $f=1 /(2 \tau)=1 / T$, where $\tau$ is the half-period and $T$ is the period of the signal, whereas for the asymmetric signal $f=1 /\left(\tau_{\mathrm{u}}+\tau_{1}\right)=1 / T$, where $\tau_{\mathrm{u}}$ and $\tau_{1}$ are the half-periods associated with $E_{\mathrm{u}}$ and $E_{1}$, respectively. In the present work the following ranges of the potential routine variables were used, $-0.2 \mathrm{~V} \leqslant E_{\mathrm{u}} \leqslant 0.8 \mathrm{~V}$; $-2.4 \mathrm{~V} \leqslant E_{1} \leqslant-1.6 \mathrm{~V} ; \quad 0.05 \mathrm{kHz} \leqslant f \leqslant 4.0 \mathrm{kHz}$; $0 \mathrm{~s}<t \leqslant 60 \mathrm{~s}$ and $0.4 \leqslant \tau_{\mathrm{u}} / \tau_{1} \leqslant 2.4$. Most of the results reported in this paper correspond to the application of a symmetric wave $\left(\tau_{u}=\tau_{1}\right)$, except otherwise stated. The RSWPR treatment was followed by a triangular potential cycling (RTPS) at $0.1 \mathrm{~V} \mathrm{~s}^{-1}$ between -0.32 and $0.64 \mathrm{~V}$ for $5 \mathrm{~min}$. The voltammogram recorded immediately afterwards allowed the electroreduction charge, $Q_{\mathrm{r}}$, to be obtained, from $Q_{\mathrm{r}}=Q_{\mathrm{a}}-Q_{\mathrm{b}}$, where $Q_{\mathrm{a}}$ and $Q_{\mathrm{b}}$ are the electroreduction charges after and before applying the RSWPS, respectively.

Occasionally, cobalt hydroxide layers, resulting from the electrochemical treatment under the optimal RSWPR conditions, were thermally treated at $480^{\circ} \mathrm{C}$ for $4 \mathrm{~h}$ under air in a quartz furnace, following the procedure recently described [6].

The electrochemical data of cobalt oxide layers resulting from the different treatments were complemented with ex situ SEM micrographs, X-ray diffractometry, infrared spectroscopy and thermal analysis data.

\section{Results}

\subsection{Voltammetric characteristics of the treated cobalt electrodes}

The base voltammogram of polycrystalline cobalt in $1 \mathrm{M} \mathrm{NaOH}$ after 5 min potential cycling at $0.1 \mathrm{~V} \mathrm{~s}^{-1}$ between -0.32 and $0.64 \mathrm{~V}$ (Fig. 1a) exhibits the conventional current peaks, namely, $I_{\mathrm{a}} / I_{\mathrm{c}}, \mathrm{II}_{\mathrm{a}} / \mathrm{II}_{\mathrm{c}}$ and $\mathrm{III}_{\mathrm{a}} / \mathrm{III}_{\mathrm{c}}$ already described in the literature $[7,8]$. The estimated peak potential values in the electrooxidation scan are $0.07,0.23$ and $0.54 \mathrm{~V}$, whereas in the electroreduction scan they are $0.53,0.22$ and $\sim-0.2 \mathrm{~V}$, the latter appearing only as a small trace. For further details about voltammograms see [7] and [8].

When a cobalt electrode in $1 \mathrm{M} \mathrm{NaOH}$ is subjected to RSWPR for $30 \mathrm{~s}$ at $E_{1}=-1.8 \mathrm{~V}, E_{\mathrm{u}}=0.5 \mathrm{~V}$ and $f=2.5 \mathrm{kHz}$, a thick hydrous cobalt oxide overlayer is formed. The corresponding stabilized voltammogram at $0.1 \mathrm{~V} \mathrm{~s}^{-1}$ (Fig. Ib) exhibits a large increase in the voltammetric charge of about 30 times that found for the blank. The treated electrode also shows a considerable enhancement of the oxygen evolution reaction

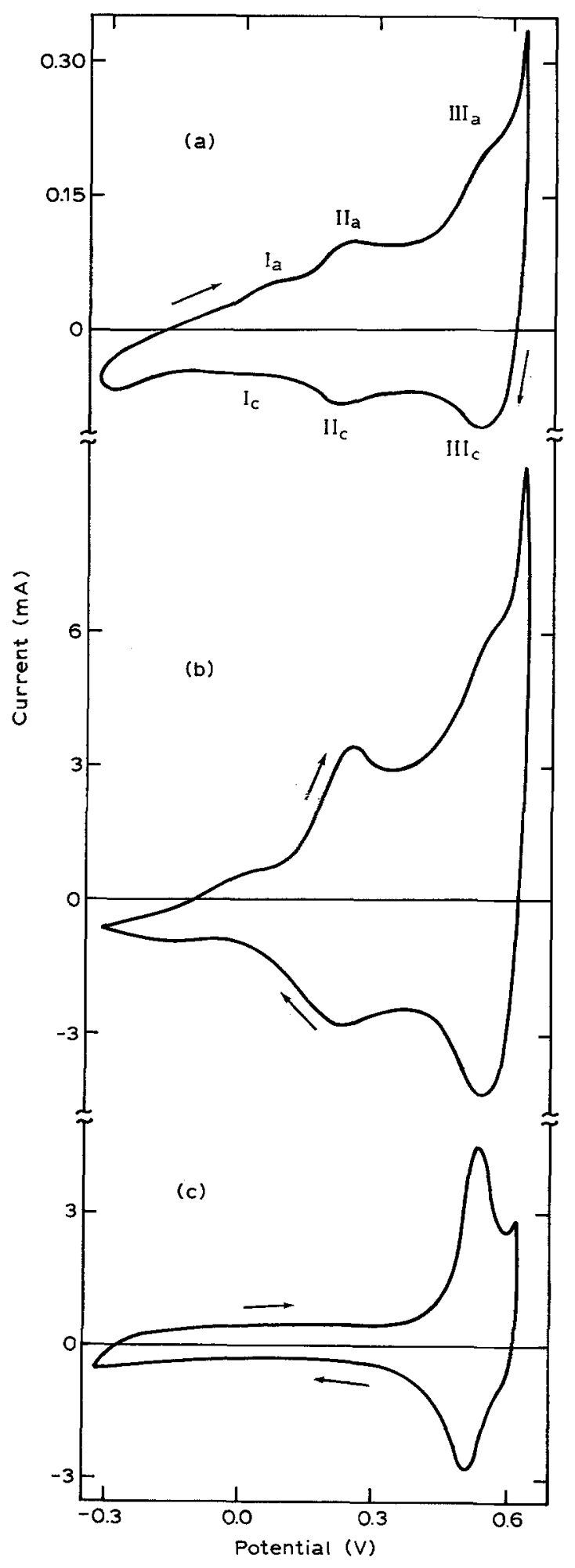

Fig. 1. Voltammograms of $\mathrm{Co}$ in $1 \mathrm{M} \mathrm{NaOH}$ at $0.1 \mathrm{~V} \mathrm{~s}^{-1}$, geometric electrode area $0.37 \mathrm{~cm}^{2}, 30^{\circ} \mathrm{C}$. (a) Untreated polycrystalline Co electrode (blank) after 5 min potential cycling between -0.32 and $0.64 \mathrm{~V}$; (b) Co electrode after the application of a symmetric RSWPR for $30 \mathrm{~s}$ at $f=2.5 \mathrm{kHz}$ between $E_{1}=-1.8 \mathrm{~V}$ and $E_{\mathrm{u}}=0.5 \mathrm{~V}$; and (c) Co electrode prepared as described in (b) and subsequently subjected to heating at $480^{\circ} \mathrm{C}$ for $2 \mathrm{~h}$.

(OER) at $0.65 \mathrm{~V}$, and becomes a precursor for a $\mathrm{Co}_{3} \mathrm{O}_{4}$ spinel overlayer [11-13].

The characteristics of the first voltammetric scan after the application of the RSWPR depends on $E_{\mathrm{u}}$. Thus, when $E_{\mathrm{u}}=0.5 \mathrm{~V}$ the electrooxidation charge of the first scan becomes only slightly greater than that resulting for the stabilized voltammogram, but this 


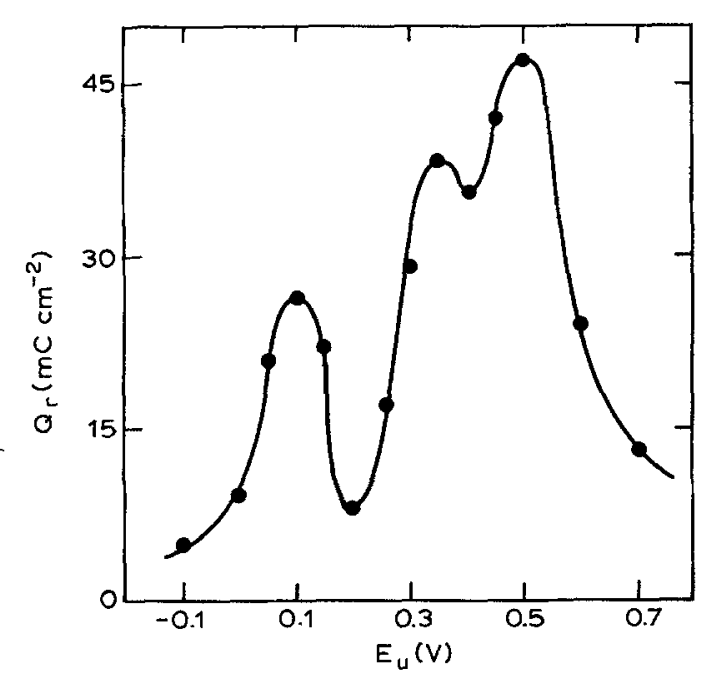

Fig. 2. $Q_{\mathrm{r}}$ against $E_{\mathrm{u}}$ plot. The Co electrodes were subjected for $30 \mathrm{~s}$ to a symmetric RSWPR between $E_{1}=-1.8 \mathrm{~V}$ and different $E_{\mathrm{u}}$ values at $f=2.5 \mathrm{kHz}, 1 \mathrm{M} \mathrm{NaOH}, 30^{\circ} \mathrm{C}$.

difference increases considerably according to $E_{\mathrm{u}}$ for $0.3 \mathrm{~V} \leqslant E_{\mathrm{u}} \leqslant 0.1 \mathrm{~V}$. This charge is probably related to the formation of soluble cobalt species, the electroreduction of the latter taking place simultaneously with the hydrogen evolution reaction (HER).

\subsection{The influence of $E_{\mathrm{u}}, E_{1}$ and $f$ on $Q_{\mathrm{r}}$}

The optimal RSWPR conditions for obtaining a relatively large amount of active material were systematically studied by changing $E_{\mathrm{u}}, E_{\mathrm{l}}$ and $f$. The amount of active material was taken as directly proportional to $Q_{\mathrm{r}}$. Thus, the $Q_{\mathrm{r}}$ against $E_{\mathrm{u}}$ plot $\left(E_{1}=-1.8 \mathrm{~V}\right.$, $f=2.5 \mathrm{kHz}$ and $t=30 \mathrm{~s}$ ) exhibits three peaked values of $Q_{r}$, at $0.1,0.35$ and $0.5 \mathrm{~V}$, respectively (Fig. 2). The potentials corresponding to the three maxima are closely related to those shown in the voltammogram of Fig. lb. On the other hand, the $Q_{\text {r }}$ against $E_{1}$ plot

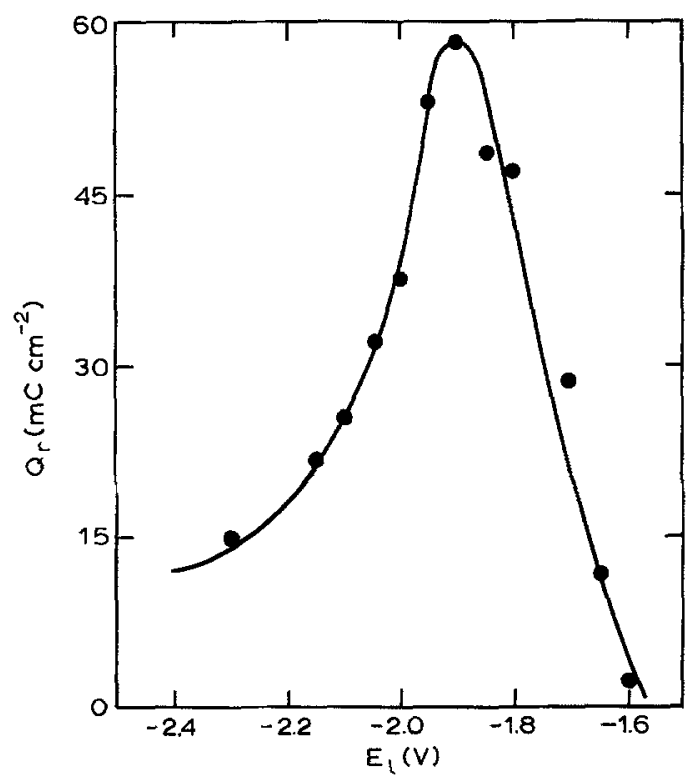

Fig. 3. $Q_{\mathrm{r}}$ against $E_{1}$ plot. The Co electrodes were subjected for $30 \mathrm{~s}$ to a symmetric RSWPR between $E_{\mathrm{u}}=0.5 \mathrm{~V}$ and different $E_{1}$ values at $f=2.5 \mathrm{kHz}, 1 \mathrm{M} \mathrm{NaOH}, 30^{\circ} \mathrm{C}$.
$\left(E_{\mathrm{u}}=0.5 \mathrm{~V}, f=2.5 \mathrm{kHz}\right.$ and $t=30 \mathrm{~s}$ ) shows up only a single peaked value of $Q_{\mathrm{r}}$ at about $-1.9 \mathrm{~V}$ (Fig. 3).

The value of $Q_{\mathrm{r}}$ depends considerably on both $f$ and $E_{\mathrm{u}}$ (Fig. 4). Thus, for $E_{\mathrm{u}}=0.1 \mathrm{~V}$ and $f=0.8 \mathrm{kHz}$ a broad peaked value of $Q_{\text {r }}$ and the formation of a pink oxide layer can be observed. For $E_{\mathrm{v}}=0.3 \mathrm{~V}$ the maximum value of $Q_{\mathrm{r}}$ also appears for $f=0.8 \mathrm{kHz}$, but in this case the electrode acquires a yellowish brown tinge. Likewise, the $Q_{\mathrm{r}}$ against $E_{\mathrm{u}}$ relationship becomes narrower and the peaked value of $Q_{\mathrm{r}}$ greater than in the preceding case. Finally, for $E_{\mathrm{u}}=0.5 \mathrm{~V}$, two peaked values of $Q_{\mathrm{r}}$ can be observed, the steepest one for $f=0.15 \mathrm{kHz}$, and another, much broader, for $f=1.2 \mathrm{kHz}$. For the latter a black compound is produced at the electrode surface. The colour changes at the electrode surface are, in principle, consistent with the formation of $\mathrm{Co}$ (II) oxide-containing layers for $E_{\mathrm{v}}<0.3 \mathrm{~V}$, and $\mathrm{Co}(\mathrm{III})$ oxide-containing layers for $E_{\mathrm{v}} \simeq 0.5 \mathrm{~V}[1,8]$.

The dependence of $Q_{\mathrm{r}}$ on $t$, the duration of the RSWPR, is shown in Fig. 5. Initially, $Q_{r}$ increases linearly with $t$, independently of $E_{\mathrm{u}},\left[\left(\Delta Q_{\mathrm{r}} / \Delta T\right)_{t \rightarrow 0} \simeq\right.$ $\left.6 \mathrm{mC} \mathrm{cm}^{-2} \mathrm{~s}^{-1}\right]$. But for $t \geqslant 3 \mathrm{~s}$ the rate of increase of $Q_{\mathrm{r}}$ depends on $E_{\mathrm{u}}$. For $E_{\mathrm{u}}=0.3 \mathrm{~V}, Q_{\mathrm{r}}$ increases to approach a limiting value, whereas for $E_{u}=0.5 \mathrm{~V}, Q_{\mathrm{r}}$ goes through a maximum value for $t \simeq 30 \mathrm{~s}$, and later decreases rather slowly.

For an asymmetric RSWPR with $E_{1}=-1.8 \mathrm{~V}$, $E_{\mathrm{u}}=0.5 \mathrm{~V}$ and $f=1 \mathrm{kHz}$ (Fig. 6), the value of $Q_{\mathrm{r}}$ reaches a maximum for $\tau_{u} / \tau_{1}=0.8$, i.e. $\tau_{u}=0.44 \mathrm{~ms}$. From data depicted in Fig. 6 it appears that a threshold value, $\tau_{u} / \tau_{1} \simeq 0.3$ is related to the increase of $Q_{r}$.

\subsection{SEM micrographs}

The hydrous cobalt oxide layers obtained after $30 \mathrm{~s}$ application of the RSWPR between $E_{1}=-1.8 \mathrm{~V}$ and $E_{\mathrm{u}}=0.1 \mathrm{~V}$ at $f=1 \mathrm{kHz}$ appear as transparent pink tinged layers. SEM micrographs of these layers show a globular spongy-like rough structure (Fig. 7a). On the other hand, the cobalt oxide layers prepared for the same $E_{1}$ and $f$ values but $E_{\mathrm{u}}=0.3 \mathrm{~V}$, acquire a yellowish-brown colour and the corresponding SEM micrographs display a non-uniform granular morphology (Fig. 7b). Finally, for $E_{\mathrm{u}}=0.5 \mathrm{~V}$, the resulting black cobalt oxide layers exhibit a rather uniform globular spongy-like structure (Fig. 7c). The particles that constitute the globular structure present sharp edges and angles.

\subsection{IR spectroscopy, thermal gravimetric and differential thermal analysis, and $X$-ray diffractometry}

Cobalt oxide samples were prepared from cobalt electrodes by applying the RSWPR for $E_{1}=-1.8 \mathrm{~V}$, $f=1 \mathrm{kHz}$, and for $E_{\mathrm{u}}=0.1 \mathrm{~V}$ (sample I), $E_{\mathrm{u}}=0.3 \mathrm{~V}$ (sample II) and $E_{\mathrm{u}}=0.5 \mathrm{~V}$ (sample III). The cobalt oxide removed from the electrode and collected from the bottom of the cell, was filtered, rinsed repeatedly 


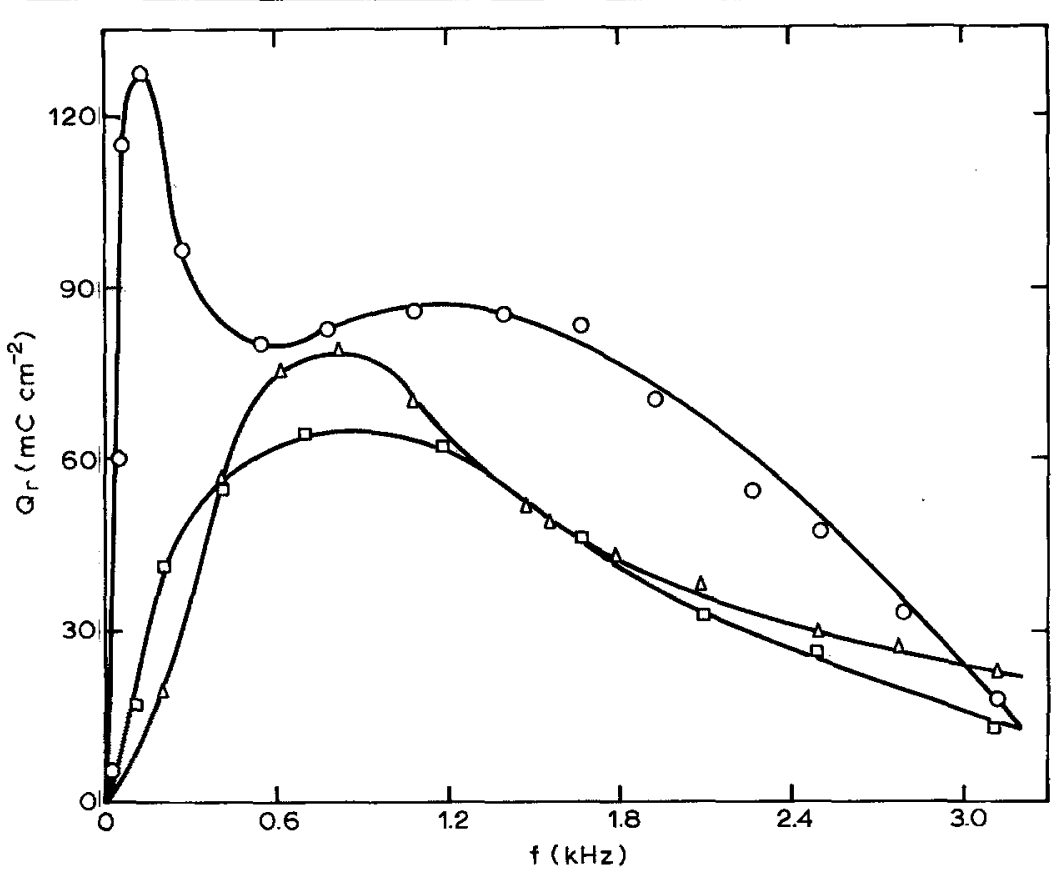

Fig. 4. $Q_{\mathrm{r}}$ against $f$ plot. The Co electrodes were subjected for $30 \mathrm{~s}$ to a symmetric RSWPR between $E_{1}=-1.8 \mathrm{~V}$ and $E_{\mathrm{u}}$ at different values of $f, 1 \mathrm{M} \mathrm{NaOH}, 30^{\circ} \mathrm{C}$. (a) $E_{\mathrm{u}}=0.1 \mathrm{~V} ;(\Delta) E_{\mathrm{u}}=0.3 \mathrm{~V} ;(0) E_{\mathrm{u}}=0.5 \mathrm{~V}$. with triply distilled water, and dried at room temperature under nitrogen. Sample I was initially a near transparent solid which, after a few minutes, turned into a brown compound. This spontaneous process was attributed to the oxidation of $\beta-\mathrm{Co}(\mathrm{OH})_{2}$ to $\mathrm{CoOOH}$ [14-16]. The sample II was also brown, whereas sample III was black.

The IR spectra of samples I and II (Fig. 8a and b) show similar shapes with a well defined absorption band at $590 \mathrm{~cm}^{-1}$. On the other hand, sample III also shows the band at $590 \mathrm{~cm}^{-1}$ in addition to other bands at 320 and $670 \mathrm{~cm}^{-1}$ (Fig. 8c). Besides, a shoulder at $560 \mathrm{~cm}^{-1}$ can be distinguished, that is, an absorption band superposed on that at $590 \mathrm{~cm}^{-1}$. The bands at 560 and $670 \mathrm{~cm}^{-1}$ were assigned to the vibrations of the $\mathrm{Co}$ (III)O $\mathrm{O}_{6}$ and $\mathrm{Co}(\mathrm{II}) \mathrm{O}_{4}$ polyhedra [17].

The IR spectra of cobalt oxide samples prepared as indicated above, and subsequently subjected to thermal treatment at $480^{\circ} \mathrm{C}$ for $4 \mathrm{~h}$, show the main absorption bands centred at 390,570 and $670 \mathrm{~cm}^{-1}$ (Fig. 8d and e) in good agreement with the spectrum of $\mathrm{Co}_{3} \mathrm{O}_{4}$ obtained by thermal decomposition of cobalt nitrate [17-19].

The thermal gravimetric analysis (TGA) of samples I and II (Fig. 9a and b) give both a weight loss of about $31 \%$ up to $450^{\circ} \mathrm{C}$, whereas the corresponding TGA of sample III shows a weight loss of about $25 \%$ involving the stripping of different types of water molecules at 50, 85, 100 and probably $200^{\circ} \mathrm{C}$ (Fig. 9). All the thermograms can be divided into two regions. The first, up to approximately $150^{\circ} \mathrm{C}$, is associated with the loss of the adsorbed and interstitial water. The temperature dependence reflects the different ways in which this water is distributed in the bulk of the oxide. In the second region, the transformation of the hydroxides into oxides (dehydroxylation) occurs. Furthermore, both phenomena can be observed in the DTA spectra, which show two endothermic signals, both coinciding with the initial stages of the corresponding regions on TGA. The dehydroxylation process shows an endothermic peak at about $220^{\circ}$.

The X-ray diffractograms of thermally treated

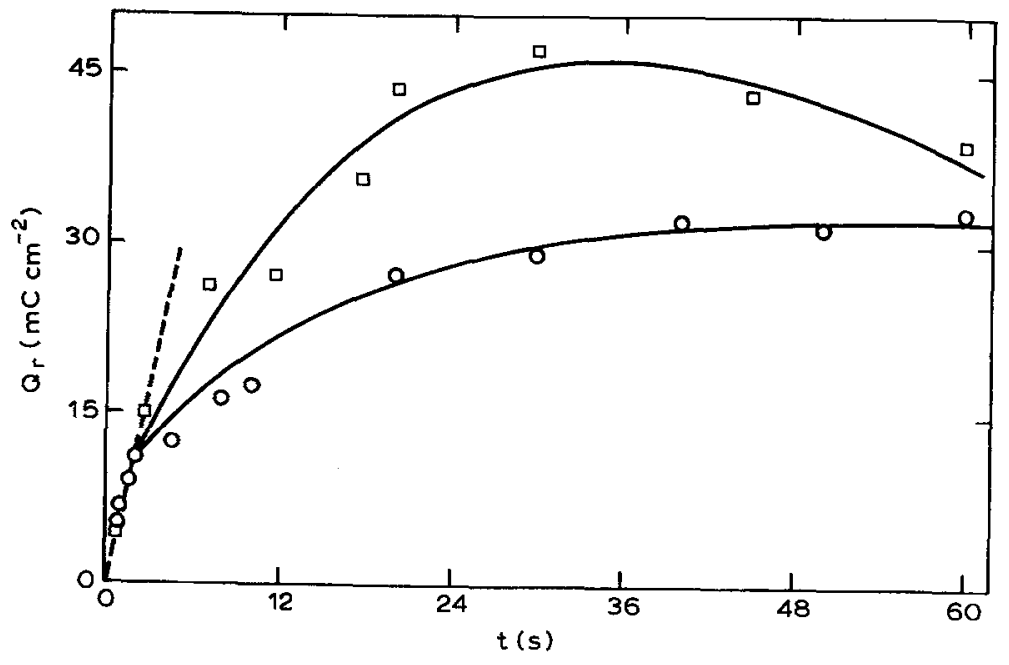

Fig. 5. $Q_{\mathrm{r}}$ against $t$ plot. The Co electrodes were subjected for different times $(t)$ to a symmetric RSWPR between $E_{1}=-1.8 \mathrm{~V}$ and different $E_{\mathrm{u}}$ values at $f=2.5 \mathrm{kHz}, 1 \mathrm{M} \mathrm{NaOH}, 30^{\circ} \mathrm{C}$. (O) $E_{\mathrm{u}}=$ $0.3 \mathrm{~V}$; (口) $E_{\mathrm{u}}=0.5 \mathrm{~V}$ 


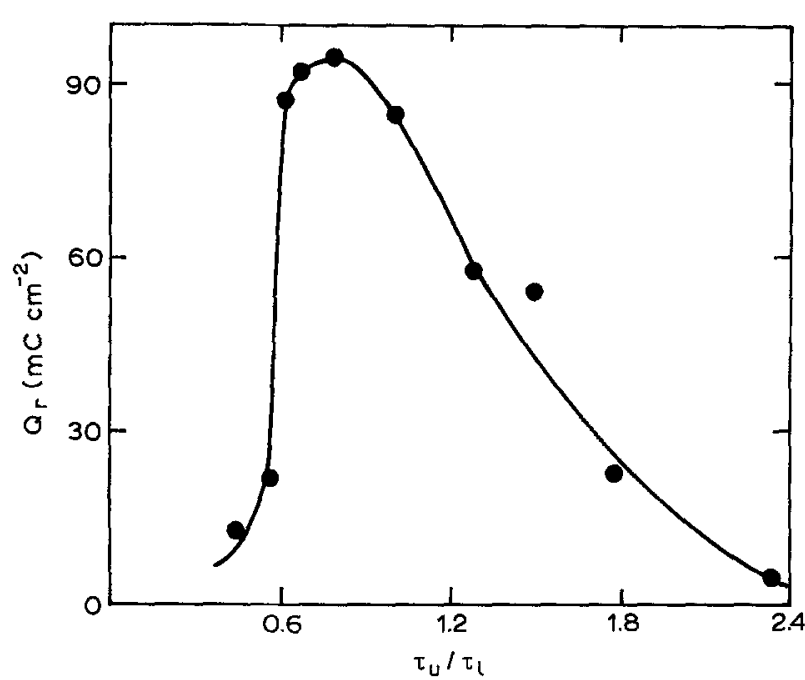

Fig. 6. $Q_{\mathrm{I}}$ against $\tau_{\mathrm{u}} / \tau_{\mathrm{I}}$ plot. The Co electrodes were subjected for $30 \mathrm{~s}$ to a symmetric RSWPR between $E_{1}=-1.8 \mathrm{~V}$ and $E_{\mathrm{u}}=0.5 \mathrm{~V}$ at $f=1 \mathrm{kHz}\left(\tau_{\mathrm{u}}+\tau_{1}=1 \mathrm{~ms}\right), 1 \mathrm{M} \mathrm{NaOH}, 30^{\circ} \mathrm{C}$.

samples (Fig. 10), give diffraction peaks corresponding to the planes $(220),(311),(222),(400),(511)$ and (440), which are typical of $\mathrm{Co}_{3} \mathrm{O}_{4}$ spinels. Otherwise, the diffractograms of electrochemically prepared cobalt oxide electrodes show, after thermal treatment at $480^{\circ} \mathrm{C}$, a progressive change from an amorphous to a crystalline structure in the direction expected for the development of the $\mathrm{Co}_{3} \mathrm{O}_{4}$-spinel structure [5].

\section{Discussion}

The results show a hydrous cobalt oxide layer can be produced by means of the RSWPR applied to Co electrodes in $1 \mathrm{M} \mathrm{NaOH}$. The stabilized voltammetric profile of the electrochemically oxidized cobalt approaches that of a $\mathrm{Co}_{3} \mathrm{O}_{4}$ spinel electrode although showing a considerable increase in the overall charge which can be attributed to an active surface area much larger than that of the untreated cobalt electrode. The coincidence between the voltammograms of a $\mathrm{Co}_{3} \mathrm{O}_{4}$ spinel electrode and that resulting from the electrochemically oxidized cobalt specimen is obtained when the latter is thermally treated at $480^{\circ} \mathrm{C}$.

In principle, there is a correlation between the number of voltammetric peaks (Fig. 1), the number of maxima appearing in the $Q_{\mathrm{r}}$ against $E_{\mathrm{u}}$ plot (Fig. 2) and the colours of the surface compounds resulting after the application of the RSWPR. According to the mechanism of $\mathrm{Co}_{3} \mathrm{O}_{4}$ formation advanced previously [5], each of the three potential ranges distinguishable in Figs 1 and 2 can be associated with a predominant species at the anodised electrode surface. In going from lower to higher potentials these compounds can be related to $\mathrm{Co}(\mathrm{OH})_{2}, \mathrm{Co}_{3} \mathrm{O}_{4}$ and $\mathrm{Co}_{2} \mathrm{O}_{3}$. According to the literature the $\mathrm{Co}(\mathrm{OH})_{2}$ species acquires a pink colour in an excess of $\mathrm{OH}^{-}$-ions in solution [20] whereas a yellowish-brown colour has been assigned to the hydrated $\mathrm{Co}_{3} \mathrm{O}_{4}[16]$ and a black colour has been related to hydrated $\mathrm{Co}_{2} \mathrm{O}_{3}[15,16]$. The sequence of colours appearing for the compounds obtained at
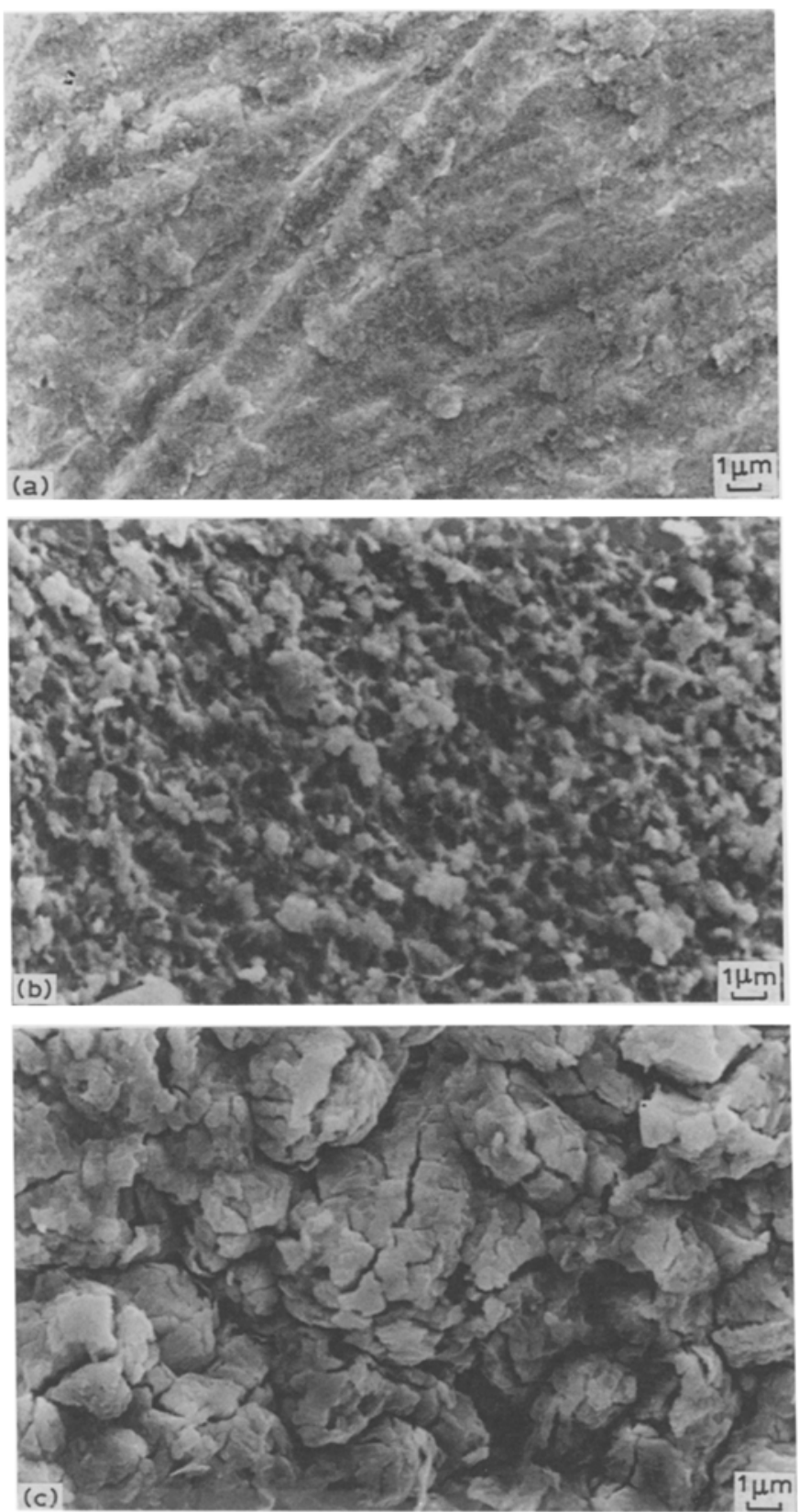

Fig. 7. SEM micrographs of the cobalt oxide layer, scale: $1 \mu \mathrm{m}$. The Co electrodes were subjected to a symmetric RSWPR in $1 \mathrm{M} \mathrm{NaOH}$, $30^{\circ} \mathrm{C}$, for $30 \mathrm{~s}$ between $E_{1}=-1.8 \mathrm{~V}$ and different $E_{\mathrm{u}}$ values at $f=1 \mathrm{kHz}$. (a) $E_{\mathrm{u}}=0.1 \mathrm{~V}$, pink tinged transparent layer; (b) $E_{\mathrm{u}}=$ $0.3 \mathrm{~V}$, yellowish-brown tinged layer; and (c) $E_{u}=0.5 \mathrm{~V}$, black coloured layer.

different potentials is consistent with thermodynamic predictions [20-23] and with the conclusions derived from studies of the electrochemical kinetics of cobalt in base solutions, particularly for the possible compounds involved in the anodic formation of thick cobalt hydroxide films in the different potential regions corresponding to peaks shown in Figs 1 and 2 $[1,24-26]$.

The formation of the hydrous cobalt oxide layer under the RSWPR indicated the fundamental role played by the anodic and cathodic half cycles in determining the characteristics of the anodic layer [5]. The present results indicate that the RSWPR treatment promotes the formation of a precursor compound in the cobalt hydroxide layer which, after the thermal 


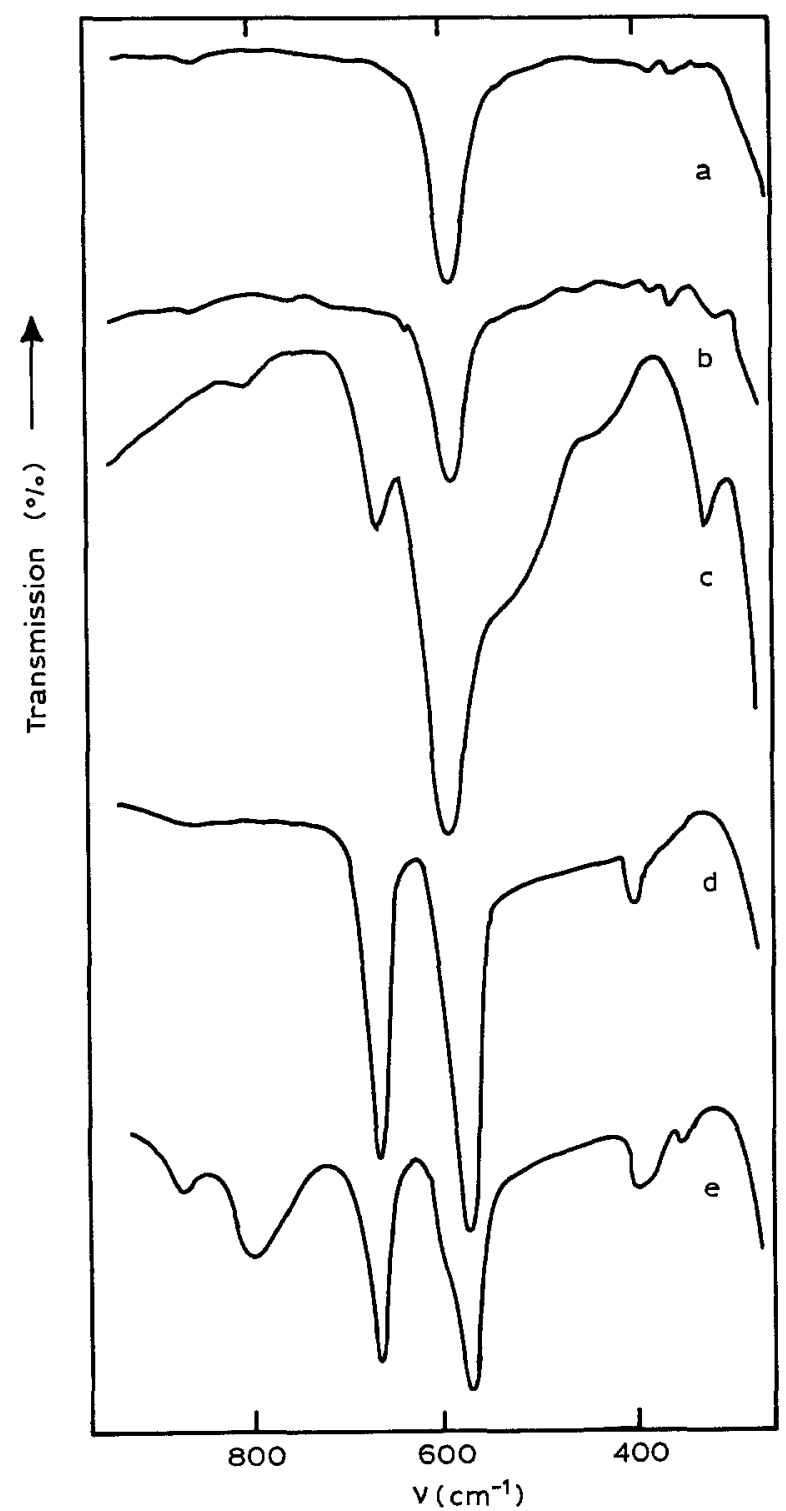

Fig. 8. Infrared spectra of Co oxide samples prepared in $1 \mathrm{M}$ $\mathrm{NaOH}, 30^{\circ} \mathrm{C}$, by using a symmetric RSWPR for $30 \mathrm{~s}$ between $E_{1}=-1.8 \mathrm{~V}$ and different $E_{\mathrm{u}}$ values at $f=1 \mathrm{kHz}$. (a) $E_{\mathrm{u}}=0.1 \mathrm{~V}$; (b) $E_{\mathrm{u}}=0.3 \mathrm{~V}$; (c) $E_{\mathrm{u}}=0.5 \mathrm{~V}$; (d) sample prepared as (a) and then thermally treated at $480^{\circ} \mathrm{C}$; and (e) sample prepared as (c) and then thermally treated at $480^{\circ} \mathrm{C}$. treatment, furnishes the $\mathrm{Co}_{3} \mathrm{O}_{4}$ spinel electrode. The precursor compound has a relatively large water content as deduced from TGA and TDA and exhibits amorphous characteristics, as shown by $\mathrm{X}$-ray diffractometry [5], in contrast to the $\mathrm{Co}_{3} \mathrm{O}_{4}$ spinel resulting from the thermal treatment.

Let us then consider the processes occurring in each half cycle during the application of the RSWPR. At potentials lower than $0.3 \mathrm{~V}$, the anodic half cycle should involve the following sequence of reactions:

$$
\begin{aligned}
\mathrm{Co}+\mathrm{OH}^{-} \rightleftharpoons \mathrm{Co}(\mathrm{OH})_{\mathrm{ad}}+e^{-} \\
\mathrm{Co}(\mathrm{OH})_{\mathrm{ad}} \rightleftharpoons \mathrm{Co}(\mathrm{O})_{\mathrm{ad}}+\mathrm{H}^{+}+e^{-}
\end{aligned}
$$

On increasing $E_{\mathrm{u}}$ one should expect that those species related to $\mathrm{Co}(\mathrm{OH})_{2}, \mathrm{Co}_{3} \mathrm{O}_{4}, \mathrm{CoOOH}, \mathrm{CoO}_{2}$ and soluble Co-anionic species be formed at different potentials. The formation of the hydrous $\mathrm{Co}(\mathrm{OH})_{2}$ layer can be expressed through a reaction involving $\mathrm{Co}(\mathrm{OH})_{\mathrm{ad}}$ species as follows:

$$
\begin{gathered}
n \mathrm{Co}(\mathrm{OH})_{\mathrm{ad}}+n \mathrm{OH}^{-}+n \cdot x \mathrm{H}_{2} \mathrm{O} \\
\rightleftharpoons n\left[\mathrm{Co}(\mathrm{OH})_{2} \cdot x \mathrm{H}_{2} \mathrm{O}\right]+n e^{-}
\end{gathered}
$$

where $n$ is the number of particles entering the formation of the $3 \mathrm{D}$ cobalt hydroxide layer. This process, which occurs at $E_{u}=0.1 \mathrm{~V}$, can be related to the voltammetric peak $I_{a}$.

The following oxidation levels appearing in the potential range of peak $\mathrm{II}_{\mathrm{a}}$ can be represented by the reactions such as:

$$
\begin{aligned}
3\left[\mathrm{Co}(\mathrm{OH})_{2} \cdot x \mathrm{H}_{2} \mathrm{O}\right] & \\
\rightleftharpoons & {\left[\mathrm{Co}(\mathrm{OH})_{2} \cdot 2 \mathrm{CoOOH} \cdot x^{\prime} \mathrm{H}_{2} \mathrm{O}\right] } \\
& +2 \mathrm{H}^{+}+z \mathrm{H}_{2} \mathrm{O}+2 e^{-}
\end{aligned}
$$

$$
\begin{aligned}
2\left[\mathrm{Co}(\mathrm{OH})_{2} \cdot x \mathrm{H}_{2} \mathrm{O}\right] & \\
\rightleftharpoons & {\left[2 \mathrm{CoOOH} \cdot x^{\prime \prime} \mathrm{H}_{2} \mathrm{O}\right]+2 \mathrm{H}^{+} } \\
& +z \mathrm{H}_{2} \mathrm{O}+2 e^{-}
\end{aligned}
$$

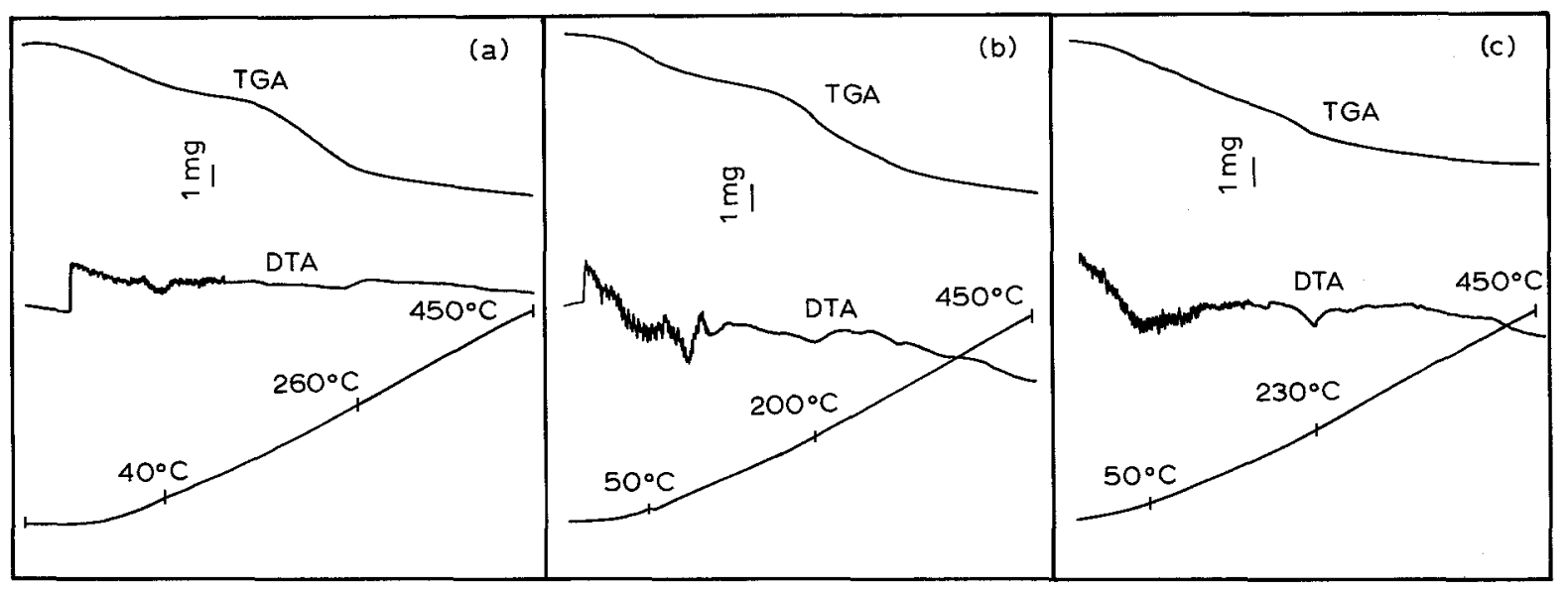

Fig. 9. Thermal gravimetric (TGA) and differential thermal (DTA) analysis run between 25 and $450^{\circ} \mathrm{C}$, for Co oxides prepared as described in Fig. 8. (a) $E_{\mathrm{u}}=0.1 \mathrm{~V}$; (b) $E_{\mathrm{u}}=0.3 \mathrm{~V}$; and (c) $E_{\mathrm{u}}=0.5 \mathrm{~V}$. 


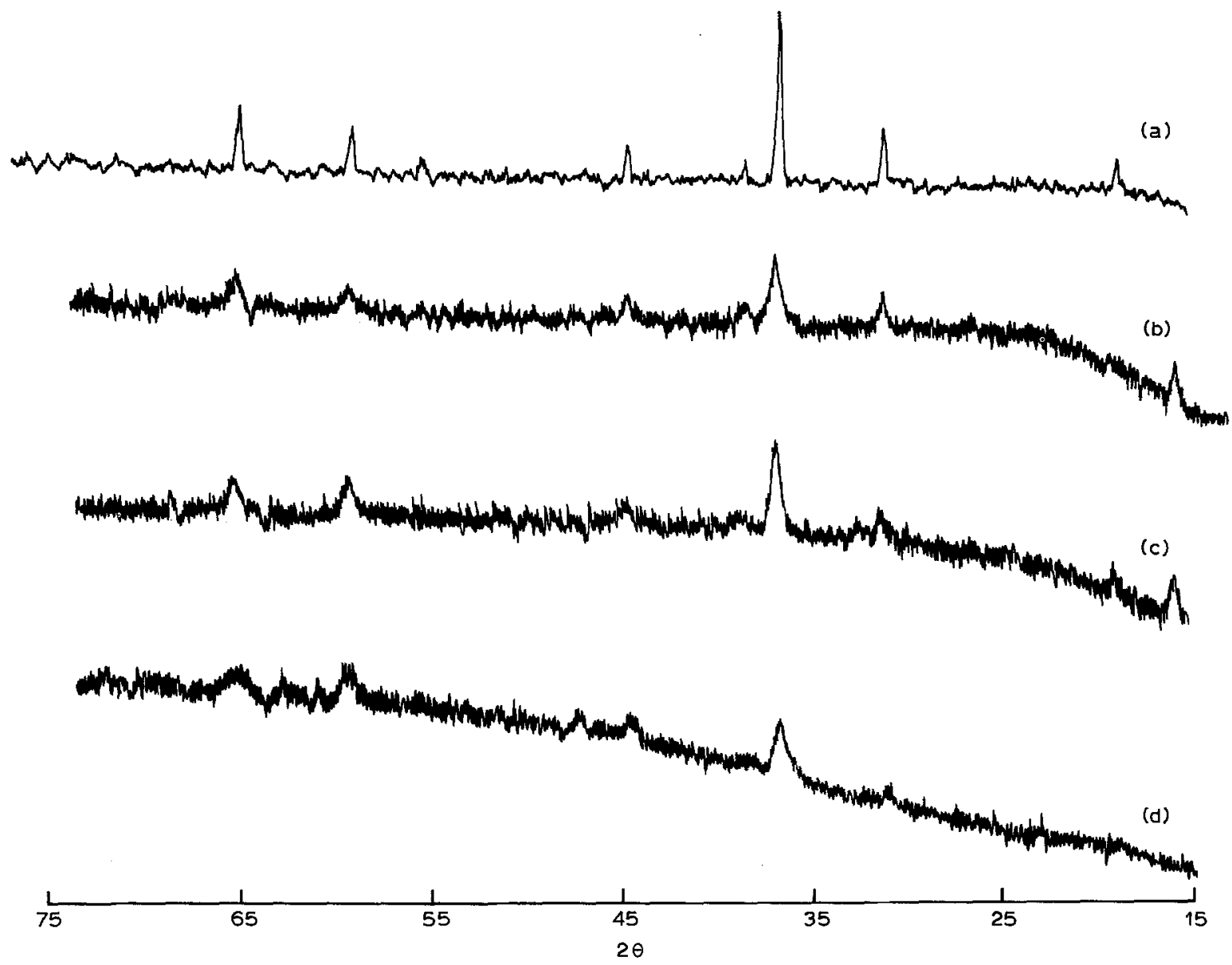

Fig. 10. X-ray diffractograms for different Co oxide samples with further thermal treatment. (a) Obtained from thermal decomposition of $\mathrm{Co}\left(\mathrm{NO}_{3}\right)_{2}$; (b) prepared as indicated in Fig. $8, E_{\mathrm{u}}=0.1 \mathrm{~V}$; (c) as for (b) with $E_{\mathrm{u}}=0.3 \mathrm{~V}$; and (d) as for (b) with $E_{\mathrm{u}}=0.5 \mathrm{~V}$.

$$
\begin{aligned}
& 2\left[\mathrm{Co}(\mathrm{OH})_{2} \cdot x \mathrm{H}_{2} \mathrm{O}\right] \\
& \rightleftharpoons\left[\mathrm{CoOOH} \cdot x^{\prime \prime \prime} \mathrm{H}_{2} \mathrm{O}\right]+\mathrm{HCoO}_{2(\mathrm{aq})}^{-} \\
& \quad+2 \mathrm{H}^{+}+z \mathrm{H}_{2} \mathrm{O}+\mathrm{e}^{-}
\end{aligned}
$$

Reaction 3a implies the formation of a gel-like compound which can be expressed by the stoichiometry $\mathrm{Co}_{3} \mathrm{O}_{4} \cdot 6 \mathrm{H}_{2} \mathrm{O}\left(x^{\prime}=4\right)[5]$ and regarded as a precursor for the $\mathrm{Co}_{3} \mathrm{O}_{4}$ formation. Reaction $3 \mathrm{~b}$ involves the complete electrooxidation of the $\mathrm{Co}(\mathrm{OH})_{2}$ to $\mathrm{CoOOH}$, for the latter the probable stoichiometry being $\mathrm{Co}_{2} \mathrm{O}_{3} \cdot 6 \mathrm{H}_{2} \mathrm{O}\left(x^{\prime \prime} \leqslant 5\right)$. Reaction 3c corresponds to the electrochemical dissolution of the $\mathrm{Co}(\mathrm{OH})_{2}$ layer yielding soluble $\mathrm{HCoO}_{2}^{-}$. It has been shown that Reactions 3a [5] and 3c [26] are relatively slow processes, so that probably Reaction $3 \mathrm{~b}$ predominates along the anodic halfcycle, in the potential range of peak $\mathrm{II}_{\mathrm{a}}$. Therefore, $\left[2 \mathrm{CoOOH} \cdot x^{\prime \prime} \mathrm{H}_{2} \mathrm{O}\right]$ is probably the type of compound mainly obtained at $E_{\mathrm{u}}=0.3 \mathrm{~V}$.

Finally, in the potential range of peak IIIa, just preceding the OER, the highest oxidation level of Co is attained through a reaction such as

$\left[2 \mathrm{CoOOH} \cdot x^{\prime \prime} \mathrm{H}_{2} \mathrm{O}\right]$

$$
\rightleftharpoons\left[2 \mathrm{CoOOH} \cdot x^{\prime \prime \prime} \mathrm{H}_{2} \mathrm{O} \cdot 2 \mathrm{OH}\right]+2 \mathrm{H}^{+}+2 e^{-}
$$

Reaction 4 is a fast reaction implying the adsorption of $\mathrm{OH}^{-}$ions on the hydrous cobalt hydroxide layer $\left(x^{\prime \prime \prime \prime} \leqslant 3\right)$ assisted by the high positive potential applied to the electrode. The stoichiometry of the product in Reaction 4 is consistent with emission Mössbauer spectroscopy data reported for the anodic oxidation of cobalt [24] although it can be formally related to that of a hydrous $\mathrm{CoO}_{2}$ species $[5,7,8,26]$.

The first reaction occurring in the cathodic half cycle of the RSWPR is related to Reaction 4 in the reverse direction, yielding $\left[2 \mathrm{CoOOH} \cdot x^{\prime \prime} \mathrm{H}_{2} \mathrm{O}\right]$. This is a fast reaction which is followed either by Reaction $3 b$ in the reverse direction or by the following one producing the precursor

$$
\begin{gathered}
3\left[\mathrm{CoOOH} \cdot x^{\prime \prime} \mathrm{H}_{2} \mathrm{O}\right]+2 e^{-} \\
\rightleftharpoons 2\left[\mathrm{Co}(\mathrm{OH})_{2} \cdot 2 \mathrm{CoOOH} \cdot x^{\prime} \mathrm{H}_{2} \mathrm{O}\right] \\
+2 \mathrm{OH}^{-}+z \mathrm{H}_{2} \mathrm{O}
\end{gathered}
$$

Soluble species are formed in the electroreduction process through a reaction such as

$\left[2 \mathrm{CoOOH} \cdot x^{\prime \prime} \mathrm{H}_{2} \mathrm{O}\right]+2 e^{-} \rightleftharpoons 2 \mathrm{HCoO}_{2(\mathrm{aq})}^{-}+x^{\prime \prime} \mathrm{H}_{2} \mathrm{O}$

coupled to the equilibrium reaction

$$
\begin{gathered}
\mathrm{HCoO}_{2}^{-}+\mathrm{H}_{2} \mathrm{O} \rightleftharpoons \mathrm{Co}_{(a q)}^{2+}+3 \mathrm{OH}^{-} \\
\rightleftharpoons \mathrm{Co}(\mathrm{OH})_{2}+\mathrm{OH}^{-}
\end{gathered}
$$


The product from Reaction 5 is accumulated principally in the electroreduction half cycle and to a lesser extent during the electroxidation half cycle. Otherwise, the $\left[2 \mathrm{CoOOH} . x^{\prime \prime} \mathrm{H}_{2} \mathrm{O}\right]$ species are gradually electroreduced to $\left[\mathrm{Co}(\mathrm{OH})_{2}, x \mathrm{H}_{2} \mathrm{O}\right]$, to $\mathrm{Co}(\mathrm{OH})_{\mathrm{ad}}$ and to $\mathrm{Co}$. The $\operatorname{Co}(\mathrm{O})$ oxidation state is probably attained only in the HER potential range, although the high local increase in $\mathrm{pH}$ may contribute to the precipitation of $\mathrm{Co}(\mathrm{OH})_{2}$ on the electrode, particularly when soluble cobalt species are formed in the electroreduction Reaction $6 \mathrm{a}$. This explains the fact that the maximum accumulation of precursor appears when the value of $E_{1}$ lies in the potential range where the simultaneous HER and complete electroreduction of the cobalt oxide species to $\operatorname{Co}(\mathrm{O})$ take place. Hence, as discussed previously [5], the increase in the electrode roughness and the amount of precursor produced in the RSWPR depend principally on the electroreduction conditions, as has been recently described for other metals in different solutions $[27,28]$.

\section{Acknowledgement}

This project was financially supported by the Consejo Nacional de Investigaciones Científicas y Técnicas (CONICET), the Comisión de Investigaciones Científicas de la Provincia de Buenos Aires (CIC) and the Stiftung Volkswagenwerk, FRG. This work was partially supported by the Regional Program for the Scientific and Technological Development of the Organization of the American States. T. Kessler is a researcher of $\mathrm{CIC}$ and Facultad de Ingeniería (UNCPBA).

\section{References}

[1] L. D. Burke, M. E. Lyons and O. J. Murphy, J. Electroanal. Chem. 132 (1982) 247.

[2] A. C. Chialvo, W. E. Triaca and A. J. Arvia, ibid. 146 (1983) 93.

[3] Idem, ibid. 171 (1984) 303.
[4] D. Burke and M. E. G. Lyons, in 'Modern Aspects of Electrochemistry, Vol. 18 (edited by J. O'M. Bockris, B. E. Conway and R. E. White), Plenum Press, New York (1986) p. 169.

[5] T. Kessler, A. Visintin, M. R. Gennero de Chialvo, W. E. Triaca and A. J. Arvia, J. Electroanal. Chem. 261 (1989) 315.

[6] M. R. Gennero de Chialvo and A. C. Chialvo, Electrochim. Acta 35 (1990) 437.

[7] H. Gómez Meier, J. R. Vilche and A. J. Arvia, J. Electroanal. Chem. 134 (1982) 251.

[8] Idem, ibid. 138 (1982) 367.

[9] W. E. Triaca, T. Kessler, J. C. Canullo and A. J. Arvia, J. Electrochem. Soc. 134 (1987) 1165.

[10] A. Visintin, J. C. Canullo, W. E. Triaca and A. J. Arvia, J. Electroanal. Chem. 267 (1989) 191.

[11] M. R. Tarasevich and B. N. Efremov, Stud. Phys. Theor. Chem. 11 (1980) 221.

[12] B. N. Efremov and M. R. Tarasevich, Elektrokhimiya 17 (1981) 1672.

[13] R. Boggio, A. Carugati and S. Trasatti, J. Appl. Electrochem. 17 (1987) 828

[14] M. Figlarz, J. Guenot and J. N. Tournemolle, J. Mater. Sci. 9 (1974) 772

[15] P. Benson, G. W. D. Briggs and W. F. K. Wynne-Jones, Electrochim. Acta 9 (1964) 275.

[16] L. D. Burke and O. J. Murphy, J. Electroanal. Chem. 112 (1980) 379.

[17] B. N. Efremov, M. R. Tarasevich, G. I. Zakharkin and S. R. Zhukov, Electrokhimiya 14 (1978) 1504.

[18] J. Preudhomme and P. Tarte, Spectrochimica Acta 27A (1971) 1817.

[19] V. N. Shalaginov, D. M. Shub, N. V. Kozlova and V. N. Lomova, Elektrokhimiya 19 (1983) 537.

[20] P. Pascal (Ed.), 'Nouveau Traité de Chimie Minérale', Vol. XVIII, Masson, Paris (1963).

[21] M. Pourbaix (Ed.), 'Atlas de Electrochemical Equilibria in Aqueous Solutions', Pergamon Press, Oxford (1966) p. 322.

[22] W. K. Behl and J. E. Toni, J. Electroanal. Chem. 31 (1971) 63.

[23] A. J. Bard, R. Parsons and J. Jordan (Eds), 'Standard Potentials in Aqueous Solutions', Marcel Dekker, New York (1985) p. 367.

[24] G. R. Simmons, E. Kellerman and L. Leidheiser, Jr, $J$. Electrochem. Soc. 123 (1976) 1276.

[25] L. D. Burke and O. J. Murphy, J. Electroanal. Chem. 109 (1980) 513.

[26] H. Willems, A. G. C. Kobussen, I. C. Vinke, J. H. W. de Witt and G. H. J. Broers, ibid. 194 (1985) 287.

[27] A. E. Bolzan, A. M. Castro Luna, A. Visintin, R. C. Salvarezza and A. J. Arvia, Electrochim. Acta 33 (1988) 1743.

[28] M. E. Vela, R. C. Salvarezza and A. J. Arvia, ibid. 35 (1990) 117. 